Molecules 2002, 7, 112-118

molecules

ISSN 1420-3049

http://www.mdpi.org

\title{
Photooxygenation of Nimonol, a Tetranortriterpenoid from Azadirachta indica. A. Juss.
}

\author{
Geetha Gopalakrishnan*, N. D. Pradeep Singh and V. Kasinath \\ Centre for Natural Products, SPIC Science Foundation, Guindy, Chennai - 600 032, India. \\ *Author to whom correspondence should be addressed; e-mail: geethagopal@hotmail.com
}

Received: 21 May 2001; in revised form: 19 December 2001 / Accepted: 21 December 2001 / Published: 28 February 2002

\begin{abstract}
Nimonol (1), a tetranortriterpenoid isolated from the leaves of Azadirachta indica A. Juss (Meliaceae), upon photolysis undergoes both Diels-Alder and ene reactions with singlet oxygen at different sites leading to 14,15,20,21-diepoxy-23-nimonolactone (3), along with nimonolide (4), which have been well-characterised. The novelty of the reported reactions lies in hitherto unreported formation of an $\alpha$-epoxide in the ring $\mathrm{D}$ in tetranortriterpenoids. The photoproduct 4 exhibited antifeedancy comparable to that of azadirachtin-A, the most potent antifeedant constituent isolated from neem.
\end{abstract}

Keywords: Photooxygenation; tetranortriterpenoid; singlet oxygen; antifeedant

\section{Introduction}

As part of our continuing studies on the photochemistry of triterpenoids of biological importance, herein we report the photooxygenation of nimonol (1), a tetranortriterpenoid having both furan and ene systems. Photooxygenation of furans [1] and olefins [2] has drawn considerable attention during the last two decades, as a convenient method for introduction of oxygen at specific sites. A literature survey revealed that reports on the photooxygenation of triterpenoids [3-7] having both furan and olefinic functional groups are scarce. 


\section{Results and Discussion}

Nimonol (1), isolated from uncrushed green leaves of Azadirachta indica (Meliaceae) [8] and possessing a $\beta$-methyl group at $\mathrm{C}$-13, according to the revised structure [9], was irradiated in benzene in a quartz vessel with a UV lamp $(254 \mathrm{~nm})$ for six hours until complete decomposition was observed. Purification of the crude product by silica gel column chromatography yielded 14,15,20,21-diepoxy23-nimonolactone (3), followed by nimonolide (4).

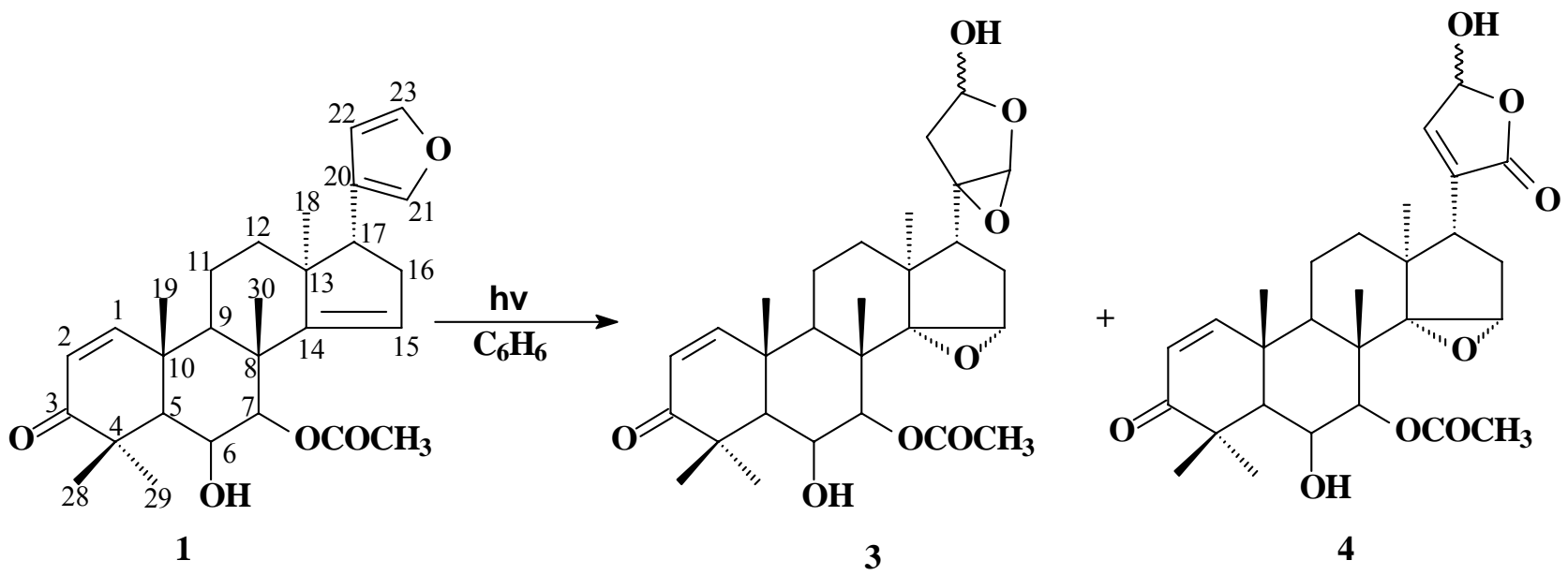

The mechanism for the formation of the photoproduct $\mathbf{3}$ is envisaged to occur as given below. The formation of the intermediate 2 can be explained by the addition of ${ }^{1} \mathrm{O}_{2}$ to furan by a Diels-Alder reaction with ${ }^{1} \mathrm{O}_{2}$ acting as the dienophile [1] and the formation of an allylic hydroperoxide at C-14 accompanied by a 1,2-shift of the double bond at C-14 to C-15 in the D ring similar to that of the ene reaction [10-12]. This unstable intermediate then further rearranges to give compound $\mathbf{3}$ :

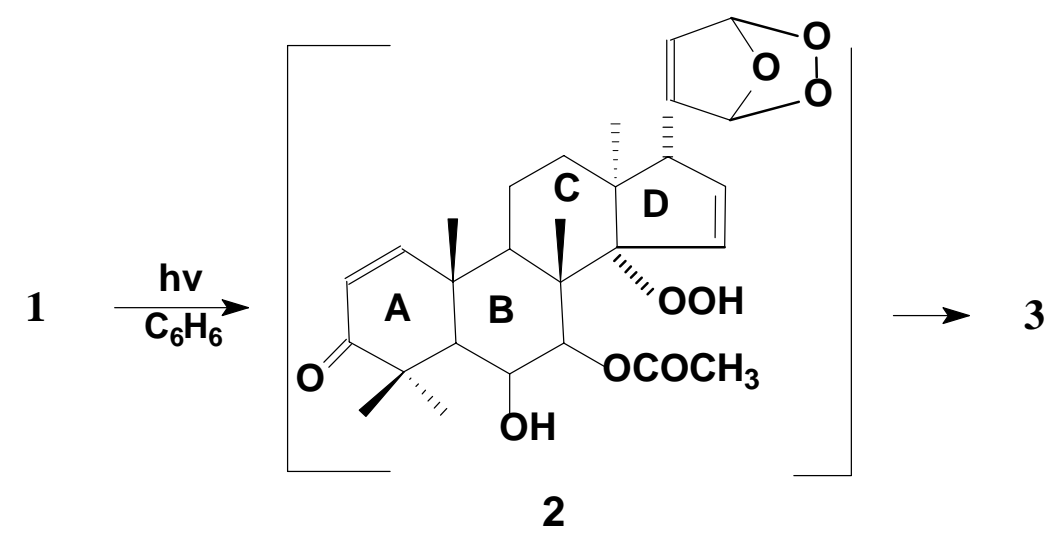

In turn, each of the two structural changes can be explained as follows: (a) the possible rearrangement of the endoperoxide functionality to an epoxy lactone in ring E may take place as depicted in the following figure: 


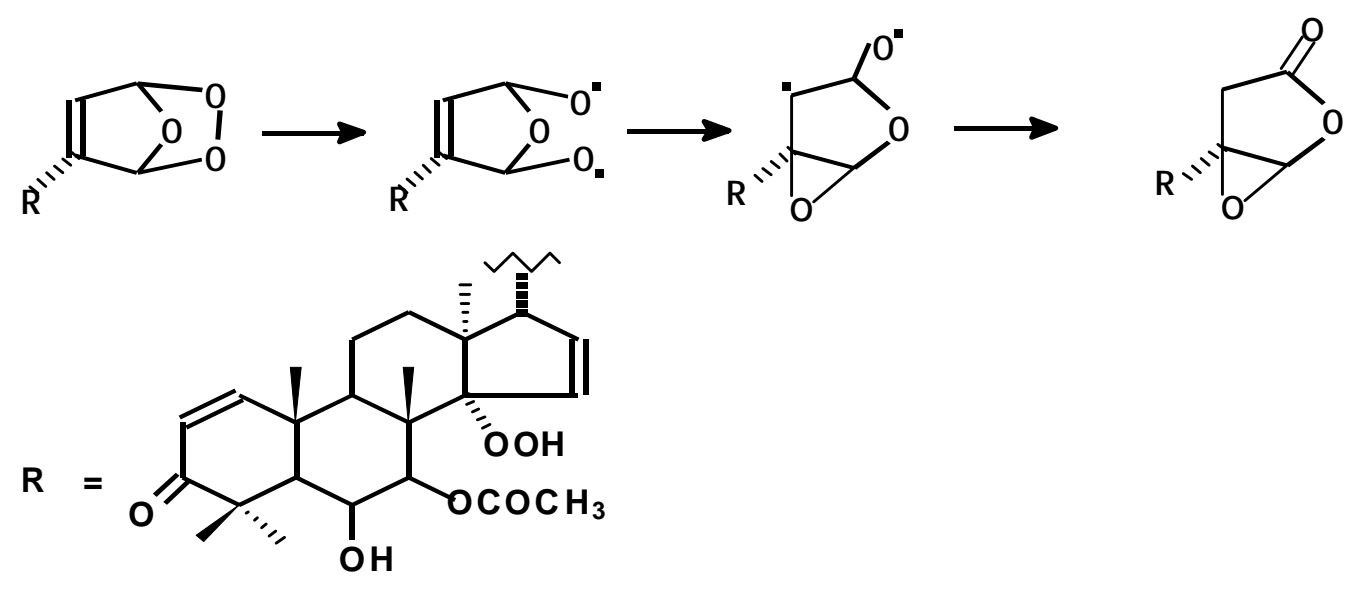

and (b), homolysis of the peroxide linkage in the allylic hydroperoxide resulting in the attachment of a C-14 alkoxy radical to C-15, thus forming an epoxide [13] between C-14 and C-15 and at the same time forming a radical at $\mathrm{C}-16$ atom, all followed by abstraction of a hydrogen atom as given below:

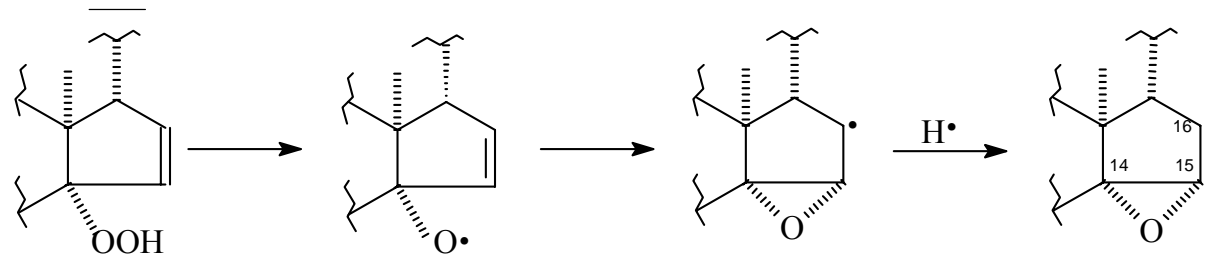

A proton elimination from a bridgehead position of an unstable ozonide-like peroxide formed by [4p+2p] cyclo addition of ${ }^{1} \mathrm{O}_{2}$ to furan followed by a subsequent rearrangement leads to the formation of photoproduct 4 , nimonolide. The above mechanism has been described in our previous paper [14, 15]. The involvement of singlet oxygen in photolysis reaction and that the singlet oxygen sensitizer it the terpenoid itself has been demonstrated in the case of photooxidation of cedrelone, a tetranortriterpenoid from Toona Ciliata. [14].

The spectral data of the photoproduct $3\left({ }^{1} \mathrm{H}\right.$ and $\left.{ }^{13} \mathrm{C}-\mathrm{NMR}\right)$ was almost identical to that of the starting compound, nimonol (1), except the former now possesses an epoxide at the $\mathrm{C} 14-\mathrm{C} 15$ bond in the D ring and an epoxy lactone in the E ring instead of an olefin and furan moieties, respectively. Evidence for these differences came from the following data: (i) one proton [triplet at $\delta 3.80 \mathrm{ppm}(\mathrm{J}=$ $2.4 \mathrm{~Hz})$ ] attached to carbon at $\delta 53.7 \mathrm{ppm}$ and attributed to $\mathrm{C}-15\left({ }^{1} \mathrm{H}-{ }^{13} \mathrm{C}\right.$ HETEROCOSY $)$ showed ${ }^{1} \mathrm{H}-{ }^{1} \mathrm{H}$ COSY connectivities with the methylene protons at $\delta 2.46$ and $2.80 \mathrm{ppm}$ ascribed to the protons at $\mathrm{C}-16$, and a quaternary carbon resonating at $\delta 77.9 \mathrm{ppm}$ ascertained the presence of an epoxide in the D-ring. The stereochemistry of epoxide is assigned to be $\alpha$, contrary to the naturally occurring $\beta$-epoxy nimonol [16] where the proton at C-15 appears as a singlet, wherein in our case it is triplet; (ii) as for the changes in the furan moiety, the ${ }^{13} \mathrm{C}$-NMR exhibited signals due to a lactone carbonyl at $\delta 175.0 \mathrm{ppm}(\mathrm{C}-23)$ and a signal at $\delta 120.4 \mathrm{ppm}$ for a methine carbon (whose proton resonates at $\delta$ $5.30 \mathrm{ppm}$ as a singlet) which could be either a dioxygenated or an olefinic methine. The possibility of an olefinic carbon is ruled out as it did not have the counterpart in ${ }^{13} \mathrm{C}$ NMR spectrum, hence the signal 
is attributed to a carbon attached to two oxygens (C-21). Further a quaternary carbon at $\delta 46.9 \mathrm{ppm}$ (C-20) and a methylene at $\delta 32.9 \mathrm{ppm}$ (the proton of which was observed as a singlet at $\delta 1.98 \mathrm{ppm}$, ${ }^{1} \mathrm{H}-{ }^{13} \mathrm{C}$ HETEROCOSY) explain the presence of a $-\mathrm{CH}_{2}-\mathrm{CO}$ group. These results all support the presence of an epoxy lactone in the furan moiety.

The ${ }^{1} \mathrm{H}$ - and ${ }^{13} \mathrm{C}$-NMR spectrum of compound 4 were similar to those of nimonol (1), except for the furan signals. The extra carbonyl resonance at $171.6 \mathrm{ppm}$ indicated an additional lactone carbonyl compared to that of the parent compound. This was confirmed by the presence of IR bands at 1792, 1718 and $1660 \mathrm{~cm}^{-1}$. The absence of $\mathrm{C} / \mathrm{H}$ signals due to furan moiety indicated that the E-ring (the furan ring) had been the site of attack, similar to the case of photoproduct 3 . The ${ }^{13} \mathrm{C}-\mathrm{NMR}$ signal at $\delta$ $96.8 \mathrm{ppm}$ (attached to the proton at $\delta 6.17 \mathrm{ppm}$ ), indicated that the carbon must be attached to two oxygen atoms. Further, this proton showed connectivity to the signal at $7.04 \mathrm{ppm}(\mathrm{H}-22)$, whose carbon resonates at $146.0 \mathrm{ppm}$ indicating clearly that the carbon connected to two oxygen atoms must be adjacent to an $\alpha, \beta$-unsaturated carbon. The presence of two other carbon signals at 137.7 and 171.6 ppm indicated that the furan ring is modified to a $\delta$-hydroxy butenolide moiety. The presence of an additional $-\mathrm{OH}$ was confirmed by the $\mathrm{D}_{2} \mathrm{O}$ labile proton at $\delta 4.91 \mathrm{ppm}$. The appearance of double signals for these carbons indicated the compound to be an epimeric mixture at C-22. The compound was then assigned to be the photooxygenated nimonol (1), named as nimonolide with a molecular formula $\mathrm{C}_{28} \mathrm{H}_{36} \mathrm{O}_{7}\left(\mathrm{M}^{+} 484\right)$.

\section{Conclusions}

Nimonol (1), which is a naturally occurring bioactive limonoid with an intact furan ring yields a novel product involving interesting Diels-Alder and ene reactions, on exposure to UV light. The novelty lies in the photolysis of intact limonoids in the absence of a sensitiser and also in the epoxidation of the D-ring under photolysis with an $\alpha$ stereochemistry, which has not been encountered in literature so far. The photoproduct 4, when tested for antifeedant activity against Spodoptera litura (Table 1), exhibited activity comparable to that of Azadirachtin-A while product $\mathbf{3}$ exhibited activity higher than the parent molecule nimonol [17].

Table 1: Antifeedant activity (\%) of limonoids and their photoproducts

\begin{tabular}{|l|l|l|l|l|}
\hline S.No & Compounds & \multicolumn{1}{|l|}{ ung } & lug & 0.5ug \\
\hline 1 & Nimonol & $32.2(2.3)$ & $55.7(3.2)$ & $32.5(7.6)$ \\
2 & Photoproduct 4 & $82.5(4.2)$ & $80.2(3.4)$ & $67.5(5.2)$ \\
3 & Photoproduct 3 & $73.5(5.7)$ & $68.7(7.7)$ & $55.3(4.2)$ \\
4 & Azadirachtin & $100.0(0)$ & $85.5(2.3)$ & $83.3(1.6)$ \\
\hline
\end{tabular}




\section{Acknowledgements}

The authors thank Dr. G.Suresh, SPIC Science Foundation and Prof. K.K. Balasubramanian, IIT, Madras for useful discussions, and Dr. S. Daniel Wesley, SPIC Science Foundation for bioactivity studies. The financial support from Department of Biotechnology, Government of India is gratefully acknowledged.

\section{Experimental}

\section{General}

UV spectra $\left(\mathrm{CHCl}_{3}\right.$ solutions) were recorded on a Shimadzu $160 \mathrm{~A}$ instrument. ${ }^{1} \mathrm{H}$ - and ${ }^{13} \mathrm{C}-\mathrm{NMR}$ spectra were recorded on a BRUKER $200 \mathrm{MHz}$ instrument at 200 and $50 \mathrm{MHz}$, respectively, using TMS as the internal standard and $\mathrm{CDCl}_{3}$ as solvent. Chemical shifts are given in terms of parts per million ( $\delta$ scale). LRMS were recorded on a Shimadzu QP 5000 mass spectrometer. Precoated silica gel plates (E-Merck, Germany, Art. 5554 Kieselgel $60 \mathrm{~F}_{254}, 0.2 \mathrm{~mm}$ thickness) were used for thin layer chromatography. Ammonium molybdate-ceric sulphate in $\mathrm{H}_{2} \mathrm{SO}_{4}$ was used as the developing agent. Analytical HPLC was carried out using a Shimadzu LC 8A system linked to a CR4A data processor. Peaks were detected at $215 \mathrm{~nm}$. A Shimpack reverse phase (C18, $25 \mathrm{~cm} \mathrm{x} 4.6 \mathrm{~mm}$ i.d.) analytical column and 60:40 methanol-water as eluent were used for the analyses. Silica gel (70-325 mesh) was used for flash column chromatography with 2:3 hexane-ethyl acetate as eluent. Photochemical reactions were carried out in a HEAOP compact photolysis apparatus model 141 supplied by HEBER Scientific, Chennai (India) and containing 8 × 8 W lamps (UV $254 \mathrm{~nm}$ ).

\section{Irradiation of Nimonol}

An air saturated solution of Nimonol (1) $\left(100 \mathrm{mg}, \lambda_{\max } 288,244 \mathrm{~nm}\right)$ in benzene $(200 \mathrm{~mL})$ was irradiated with a UV lamp system $(254 \mathrm{~nm}, 8 \times 8 \mathrm{~W})$ for six hours at the end of which the complete decomposition of nimonol 1 was confirmed by TLC (eluent: $60 \%$ ethyl acetate in $n$-hexane). The solvent was removed under reduced pressure. The product was chromatographed on silica gel (flash, 70-325 mesh; 40\% ethyl acetate in hexane) under nitrogen atmosphere to yield compound $\mathbf{3}$ (40 mg, $41 \%$ ) followed by compound 4 (24 mg, $28.6 \%)$.

\section{Analytical and Spectral Data.}

Compound 3: $\mathrm{Mp} 124^{\circ} \mathrm{C}$; UV $\lambda_{\max }(\mathrm{nm}): 251(\varepsilon=7651)$ and $254(\varepsilon=7021) ; \mathrm{IR} v_{\max } / \mathrm{CHCl}_{3} / \mathrm{cm}^{-1}: 816$, 1752, 1718, 1660, 1593, 1449, 1372, 1254, 1084, 1062, 646; ${ }^{1} \mathrm{H}-\mathrm{NMR}(\delta): 7.05$ (1H, $\left.d, \mathrm{~J} 10, \mathrm{H}-1\right)$, $5.84(1 \mathrm{H}, d, \mathrm{~J} 10, \mathrm{H}-2), 5.33(1 \mathrm{H}, d, \mathrm{~J} 5.3, \mathrm{H}-7), 5.30(1 \mathrm{H}, s, \mathrm{H}-21), 4.30(1 \mathrm{H}, d d, \mathrm{~J} 11.4,3, \mathrm{H}-6)$, 3.80(1H, $t$, J 2.4, H-15), 2.86 (1H, $d, \mathrm{~J} 3.5, \mathrm{H}-17), 2.80$ (1H, $m, \mathrm{H}-16 \mathrm{a}), 2.46$ (1H, $m, \mathrm{H}-16 \mathrm{~b}), 2.27(1 \mathrm{H}$, $m, \mathrm{H}-9), 2.23$ ( $1 \mathrm{H}, d, \mathrm{~J} 4.9, \mathrm{H}-5), 2.05$ (1H, $m, \mathrm{H}-11 \mathrm{a}), 1.98(2 \mathrm{H}, s, \mathrm{H}-22), 1.98\left(3 \mathrm{H}, s,-\mathrm{OCOC}_{3}\right)$, 1.96 (2H, $m, \mathrm{H}-12), 1.67$ (1H, $m, \mathrm{H}-11 \mathrm{~b}), 1.33$ (3H, $s, \mathrm{Me}), 1.24$ (3H, $s, \mathrm{Me}), 1.17$ (3H, $s, \mathrm{Me}), 1.13$ 
$(3 \mathrm{H}, s, \mathrm{Me}), 1.05(3 \mathrm{H}, s, \mathrm{Me}) ;{ }^{13} \mathrm{C}-\mathrm{NMR}(\delta): 205.0(\mathrm{C}-3), 171.8\left(-\mathrm{OCOCH}_{3}\right), 157.4(\mathrm{C}-1), 126.1(\mathrm{C}-2)$, 120.4 (C-21), 175.0 (C-23), 78.9 (C-7), 77.9 (C-14), 67.9 (C-6), 53.7 (C-15), 51.0 (C-13), 49.8 (C-5), 46.9 (C-20), 45.4 (C-8), 43.9 (C-10), 43.0 (C-17), 40.4 (C-4), 37.1(C-9), 33.7 (C-16), 32.9 (C-22), 31.8 (Me), 29.6 (C-12), $27.8(\mathrm{Me}), 21.1\left(-\mathrm{OCOCH}_{3}\right), 20.8$ (Me), 20.1(Me), 20.1(Me), 16.4 (C-11); EI/MS $\mathrm{m} / \mathrm{z} 500\left(\mathrm{M}^{+}\right)$.

Compound 4: Mp 136-138 ${ }^{\circ} \mathrm{C}$; UV $\lambda_{\text {max }}(\mathrm{nm}): 240$ ( $\left.\varepsilon=9448\right)$, and $254(\varepsilon=8109)$; IR $v_{\max }\left(\mathrm{cm}^{-1}\right): 3352$, 2975, 2860, 1792, 1752, 1718, 1698, 1583, 1445, 1310, 1024, 970, 880, 842, 647, 611; ${ }^{1} \mathrm{H}-\mathrm{NMR} \delta$ : $7.12(1 \mathrm{H}, d, \mathrm{~J} 10, \mathrm{H}-1), 7.04$ (1H, $d, \mathrm{~J} 7, \mathrm{H}-21), 6.17$ (d,1H, J 7, H-22), 5.89 (1H, $d, \mathrm{~J} 10, \mathrm{H}-2), 5.37$ $(1 \mathrm{H}, t, \mathrm{~J} 7, \mathrm{H}-15), 5.37(1 \mathrm{H}, d, \mathrm{~J} 2.8, \mathrm{H}-7), 4.91$ (brs, $\mathrm{D}_{2} \mathrm{O}$ exchangeable, 1H, -OH), $4.37(1 \mathrm{H}, d d, \mathrm{~J}$ 11.6, 3, H-6), 2.81 (1H, m, H-17), 2.57 (1H, m, H-12a), 2.44 (1H, d, J 11.6, H-9), 2.23 (1H, m, H-5), $2.17(1 \mathrm{H}, m, \mathrm{H}-12 \mathrm{~b}), 2.05\left(s, 3 \mathrm{H},-\mathrm{O}-\mathrm{CO}_{-} \mathrm{H}_{3}\right), 2.04(1 \mathrm{H}, m, \mathrm{H}-16 \mathrm{a}), 1.75-1.65\left(1 \mathrm{H}\right.$, brs, $\mathrm{D}_{2} \mathrm{O}$ exchangeable, -OH), $1.76(1 \mathrm{H}, m, \mathrm{H}-16 \mathrm{~b}), 1.81-1.72(2 \mathrm{H}, m, \mathrm{H}-11), 1.40(3 \mathrm{H}, s, \mathrm{Me}), 1.30(3 \mathrm{H}, s$, $\mathrm{Me}), 1.27$ (3H, s, Me), $1.13(3 \mathrm{H}, s, \mathrm{Me}), 0.90$ (s,3H, Me); ${ }^{13} \mathrm{C}-\mathrm{NMR} \delta: 206.2(\mathrm{C}-3), 172.0\left(-\mathrm{OCOCH}_{3}\right)$, 171.6, 171.4 (C-21), 158.5 (C-14), 157.6 (C-1), 146.0, 145.7 (C-22), 137.7, 137.6 (C-20), 126.1(C-2), 119.3 (C-15), 96.8, 96.4 (C-23), 79.1(C-7), 68.1(C-6), 50.6 (C-17), 49.9 (C-5), 47.2 (C-13), 45.5 (C-8), 43.3 (C-10), 40.6 (C-4), 36.9 (C-9), 34.3 (C-16), 32.7 (C-12), 31.9 (Me), 27.3 (Me), $21.2\left(-\mathrm{OCO}^{-} \mathrm{H}_{3}\right)$, $21.1(\mathrm{Me}), 20.9(\mathrm{Me}), 20.3(\mathrm{Me}), 16.4(\mathrm{C}-11)$; EI/MS m/z $484\left(\mathrm{M}^{+}\right)$.

\section{References}

1. Feringa, B. L. Photo oxidation of furans. Rec. Trav. Chim, Pays-Bas, 1957, 106, 469-488.

2. Gollinick, K. Advan. Photochem, 1968, 6,1-122.

3. Jarvis, A.P; Johnson, S.; Morgan, E.D.; Simmonds, M.S.J.; Blaney, W.M. Photooxidation of nimbin and salannin - tetranortriterpenoids from neem tree, J. Chem. Ecol., 1997, 23, 2841-2860.

4. Purushothaman, K.K ; Duraiswamy, K.; Connolly, J.D. Tetranortriterpenoids from Melia dubia, Phytochemistry, 1984, 23, 135-137.

5. Johnson, S.; Morgan, E.D.; Wilson, I.D.; Spraul, M.; Hofmann, M. Photoisomerization of azadirachtin studied by high performance liquid chromatography coupled to high field proton NMR spectroscopy, J. Chem. Soc. Perkin Trans 1, 1994,1499-1502.

6. Burke, B.A.; Chan, W.R.; Magnus, K.E.; Taylor, D.R. Extractives of Cedrela odorata L.-III. The structure of photogedunin, Tetrahedron, 1969, 25, 5007-5011

7. Grimminger, W.; Kraus, W. Photooxidation of von 3-subsutituierten furanen in aprotischen Losungmittelin, Leibigs Ann. Chem., 1979, 1571-1576.

8. Siddiqui, S.; Siddiqui, D.S.; Faizi, S.; Mahmood, T. Isolation of tetranortriterpenoid from Azadirachta indica, Phytochemistry, 1984, 23, 2899-2901.

9. Suresh, G.; Narasimhan, N.S.; Palani, N. Structure of Nimonol from fresh whole green leaves of Azadirachta indica, Phytochemistry, 1997, 45, 807-810.

10. Berson, J.A.; Wall, R.G.; Perlmutter, H.D. Preference for endoid addition in the ene system, $J$. Amer. Chem. Soc, 1966, 88, 187-188. 
11. Nickson, A.; Bagli, J.F. Reactivity and Geometry in Allylic Systems, J. Amer. Chem. Soc, 1961, 83, 1498-1508.

12. Lutz, R.F.; Welstead Jr., W.J.; Bass, R.G.; Dale, J.I. Sterochemistry of photosensitized oxygenation of monoolefins, J. Org. Chem, 1962, 27, 1111-1112.

13. Pfoertner, K.H. Alkenes: Photo-oxidation; In Photochemistry in Organic Synthesis, Coyle, J.D., editor; The Royal Society of Chemistry: Great Britain, 1986, pp. 189-209

14. Gopalakrishnan, G.; Pradeep Singh, N.D.; Kasinath, V.; Malathi, R.; Rajan, S.S. Photooxidation of Cedrelone, a tetranortriterpenoid from Toona ciliata, Photochem. Photobio., 2000, 72, 464-466.

15. Gopalakrishnan, G.; Pradeep Singh, N.D.; Kasinath., V. Photomediated transformation of Salannin, a tetranortriterpenoid from Azadirachta indica A. Juss, Molecules, 2001, 6, 551-556.

16. Govindachari, T.R.; Malathi R.; Gopalakrishnan, G.; Suresh, G.; Rajan, S.S. Isolation of a new tetranor-triterpenoid from the uncrushed green leaves of Azadirachta indica, Phytochemistry, 1999, 52, $1117-1119$.

17. Pradeep Singh, N.D. Ph.D.Thesis, University of Madras, November 2000.

Sample Availability: Samples of compounds 1 (20 mg), 3 and $\mathbf{4}(3 \mathrm{mg}$.) are available from the authors.

(C) 2002 by MDPI (http://www.mdpi.org). Reproduction is permitted for noncommercial purposes. 